Portland State University

PDXScholar

1982

\title{
Language development and visual-motor integration in the preschool child
}

Andrea Lynn Perry Graham

Portland State University

Follow this and additional works at: https://pdxscholar.library.pdx.edu/open_access_etds

Part of the Child Psychology Commons, Linguistics Commons, and the Speech Pathology and Audiology Commons

Let us know how access to this document benefits you.

\section{Recommended Citation}

Graham, Andrea Lynn Perry, "Language development and visual-motor integration in the preschool child" (1982). Dissertations and Theses. Paper 3168.

https://doi.org/10.15760/etd.3157

This Thesis is brought to you for free and open access. It has been accepted for inclusion in Dissertations and Theses by an authorized administrator of PDXScholar. Please contact us if we can make this document more accessible: pdxscholar@pdx.edu. 
AN ABSTRACT OF THE THESIS OF Andrea Lynn Perry Graham for the Master of Science in Speech Communication, with an emphasis in Speech Pathology/Audiology, presented May $18,1982$.

Title: Language Development and Visual-Motor Integration in the Preschool Child

APPROVED BY MEMBERS OF THE THESTSACOMMITTEE:

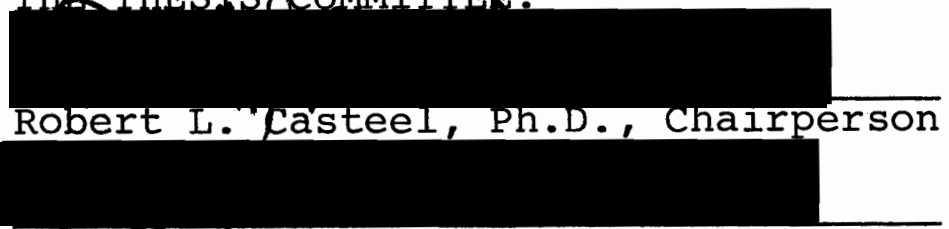

Mary E. Gordon, M.S.

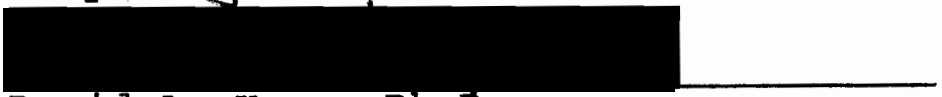

David A. Krug, Ph.D.

The purpose of this study was to compare the visualmotor integrative abilities of preschool children with their articulatory and syntactical development. Two questions were posed: Do children having accelerated visual-motor integrative skills perform at a higher level than children having delayed visual-motor integration skills in 1) their articulation proficiency, and 2) their syntactical abilities?

Twenty-nine preschool children were selected from Portland area preschool and daycare centers on the basis of age, parental permission for participation, lack of known organic involvement, and ability to copy geometric 
designs. Each subject was evaluated with the Developmental Test of Visual-Motor Integration and had received a score one standard deviation, or more, above or below their chronological age. All subjects met a criterion of 90 or above on the intelligence quotient on the Peabody Picture Vocabulary Test. Each child was then given the Templin-Darley Screening Test for Articulation, and the Carrow Elicited Language Inventory to determine their skill levels.

After the articulation testing and the language testing, the subjects demonstrating "high visual-motor integration", and those demonstrating "low visual-motor integration" were compared according to their articulation proficiencies and their syntactical language abilities. Two statistical measures of one-tailed $\underline{t}$-tests for independent measures, and Chi square analysis were computed to determine the significance of the high (HVMI) and low (LVMI) visual-motor integration groups with respect to articulation and syntactic language abilities. Results of the t-tests indicated that there was not a statistical difference between articulation skills of the HVMI and LVMI groups, and that there was a marginal significance between syntax and visual-motor integration. Further analysis demonstrated an "error" in the t-test significance; this significance appeared to be an artifact of extreme scores on a small sample. 
From examination of the data in this study it was concluded: 1) there was no significant difference between visual-motor integration and articulation skills when preschool children were identified by their fine motor skills; and 2) there was no significant difference between visual-motor integration and syntactical language skills when preschool children were identified by their fine motor skills. 


\section{LANGUAGE DEVELOPMENT AND VISUAL-MOTOR INTEGRATION IN THE PRESCHOOL CHILD}

\section{by}

ANDREA LYNN PERRY GRAHAM

A thesis submitted in partial fulfillment of the requirements for the degree of

MASTER OF SCIENCE IN SPEECH COMMUNICATION :

with an emphasis in SPEECH PATHOLOGY/AUDIOLOGY

Portland State University 
TO THE OFFICE OF GRADUATE STUDIES AND RESEARCH

The members of the committee approve the thesis of Andrea Lynn Perry Graham presented May 18, 1982.

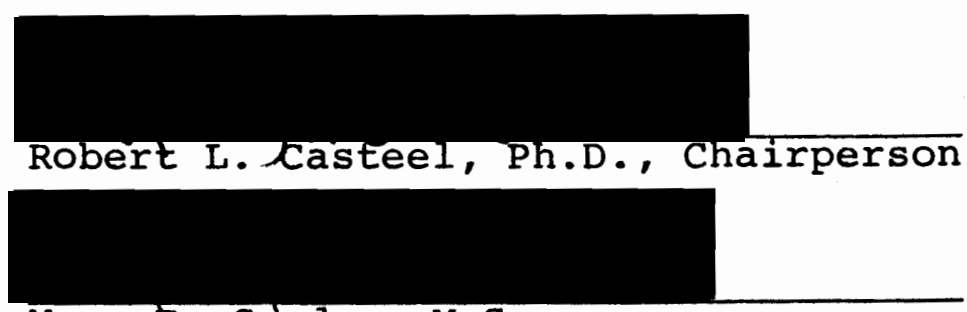

Mary E. Gordon, M.S.



APPROVED :

Theodore G. Grove, Head, Department of

Speech Communication

Stanléy E. Raúch, Dean, Graduate Studies and Research 


\section{ACKNOWLEDGMENTS}

I am deeply grateful and would like to express my sincere thanks to those people whose assistance made the completion of this thesis possible, a project which I procrastinated and questioned at various times.

I would like to extend a very warm thank you to Dr. Robert Casteel, the chairperson of my thesis committee for his continuing patience, support and understanding, even during my "dry" writing periods. Without his help this thesis would not have been possible.

I would also like to express my appreciation to Mary Gordon, and Dr. Dave Krug for their reading and re-reading of this thesis in its various stages, and for their helpful feedback. Also, I would like to thank Ted Grove for his assistance with the statistical methodology and analysis, an area which elicited panic and frustration in this author.

And, finally, thanks to David, my best friend and husband, who unconditionally gave his love, understanding and support over the years. Thanks, Babe. 
I INTRODUCTION AND PURPOSE OF THE

Introduction . . . . . . . . . . . . 1

Purpose of the Investigation . . . . . . 4

Operational Definitions . . . . . . 4

II REVIEW OF THE LITERATURE . . . . . . . 7

Early Identification . . . . . . . . 7

Visual Perception, Visual-Motor 11

Perception and Academic/Intellectual

Development.

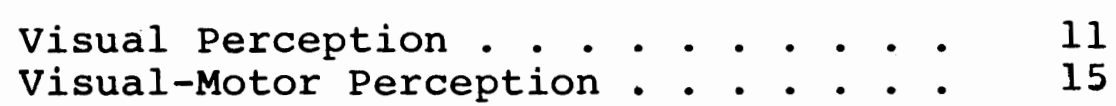

Language Development, Visual-Motor 19

Integration and the Learning Disabled

Child . . . . . . . . . . . . . 19

Verbal Cognitive Functioning . . . . 19

Language Development and Visual

Motor Integration . . . . . . . . 22

Syntactical Language and

Articulation ........ . . 25

III METHODS AND PROCEDURES . . . . . . . . 29

Subjects . . . . . . . . . . . . . 29

Instrumentation . . . . . . . . . 30

Procedures . . . . . . . . . . 32

Statistical Analysis of Data . . . . . 33 
PAGE

CHAPTER

IV

RESULTS AND DISCUSSION • . • . . • • . 35

Results . . . . . . . . . . . 35

Discussion of Results . . . . . . . . 39

V SUMMARY AND IMPLICATIONS . . . . . . . . . 45

Summary . . . . . . . . . . . . . . 45

Research Implications . . . . . . . . 47

BIBLIOGRAPHY . . . . . . . . . . . . . . . . . 49

APPENDICES . . . . . . . . . . . . . . . 54

A Parent Permission and Parent Permission Record . . . . . . . . . . . 54-55

B Summarized Data Collection for Low VisualMotor Integration Subjects . . . . . . 56

C Summarized Data Collection for High Visual-Motor Integration Subjects . . . . 57

D Comparison of Low Visual-Motor Integration (LVMI) Deviations and Templin-Darley Articulation Test Error Scores . . . . . 58

E Comparison of High Visual-Motor Integration (HVMI) Deviations and Templin-Darley Articulation Test Error Scores . . . . . 59

F Comparison of Low Visual-Motor Integration (LVMI) Deviations and Carrow Elicited Language Inventory (CESI) Error Scores . . 60

G Comparison of High Visual-Motor Integration (HVMI) Deviations and Carrow Elicited Language Inventory (CELI) Error Scores . . 
H Total Scores from Low Visual-Motor Integration subjects. (LVMI) on Carrow Elicited Language Inventory (CELI) . . .

I Total Scores from High Visual-Motor Integration Subjects (HVMI) on Carrow Elicited Language Inventory (CELI) . . . .

J Error Type Scores from Low Visual-Motor Integration Subjects. (LVMI) on the Carrow Elicited Language Inventory (CELI) . . . . 64

K Error Type Scores from High Visual-Motor Integration subjects (HVMI) on the Carrow Elicited Language Inventory CELI) $\cdot \cdot \cdot \cdot \cdot 65$

L Summary of Error Types on the Carrow Elicited Language Inventory (CELI) with Low Visual-Motor Integration subjects (LVMI) by Grammatical Categories . . . . 66

M Summary of Error Types on the Carrow Elicited Language Inventory (CELI) with High Visual-Motor Integration subjects (HVMI) by Grammatical Categories . . . . . 


\section{LIST OF TABLES}

TABLE

PAGE

I. Comparison of Raw Scores on Templin-Darley

Diagnostic Test for Articulation Showing

Means, Standard Deviations, and $\underline{t}$-Score

Values for Low Visual-Motor Integration

(LVMI) and High Visual-Motor Integration

(HVMI) Groups . . . . . . . . . . . 36

II. Group Distribution Scores on Templin-Darley

Diagnostic Test for Articulation Using

Chi Square $\left(x^{2}\right)$ Analysis . . . . . . 37

III. Comparison of Raw Scores on the CELI Showing

Means, Standard Deviations, and $\underline{t}$-Score

Values for Low Visual-Motor Integration

(LVMI) and High Visual-Motor Integration

(HVMI) Groups . . . . . . . . . . . 38

IV. Group Distribution of Scores on Carrow Elicited

Language Inventory (CELI) Using Chi Square

$\left(x^{2}\right)$ Analysis . . . . . . . . . . 39

v. Comparison of Developmental Test of Visual-

Motor Integration (VMI) Deviations and

Carrow Elicited Language Inventory (CELI)

Error Scores . ............. . 4 42 
CHAPTER I

INTRODUCTION AND PURPOSE OF THE INVESTIGATION

Introduction

The recent surge of interest in children with learning disorders represents the convergence of medical, psychological, educational, visual, and speech-language specialists. Research on child development has supported the notion that early childhood is an important developmental period (Wolfsenberger, 1965; Keogh and Becker, 1973; Eaves, Kendall and Crichton, 1974; and Bloom and Lahey, 1978). The belief in the educational importance of these years may be seen in the growth in the number of formal programs offered to young children. More states now offer mandatory kindergarten programs than in the past; more models for preschool education are present than ever before; more programs are proposed and offered for infants and toddlers; and increased attention has been directed towards the improvement of day-care facilities (Graf, 1975). Furthermore, recent federal law, under the Public Law 94-142, "The Education for All Handicapped Children Act", has required that the state must provide special education services for all identified handicapped children. This is 
to include, when necessary, the early identification and assessment of handicapping conditions. The increasing emphasis on the early childhood years has been beneficial for it has allowed for early intervention, giving teachers and specialists the opportunity to work with parents and children before the handicapping condition interferes with further development.

Researchers have compared visual and visualintegrative abilities with intelligence tests, achievement tests, reading readiness skills, psycholinguistic abilities and functional articulation, in attempts to diagnose component factors of learning and academic success. Most assessments previously have been done primarily with school age children in the kindergarten and elementary grades. Results reported by several authors (Lachman, 1960; Szliwowski, 1969; Birch and Belmont, 1965; Tsvetkova, 1974) suggest that a reading or learning disability is characterized by immaturity or a developmental lag in the modality integration of visual and motor perceptual skills. Speech and language are also developmental skills which are cross modality. Bloom and Lahey (1978) designate that the most critical period of language development is the first three to four years of life. This is the time that the speech and language skills are developmentally acquired, and these are the skills that the child brings to the beginning 
academic setting, whether it be the kindergarten or first grade. Perhaps by attempting to identify, describe and classify the components of a language and learning disability, specialists can hope to understand, and eventually to explain how language and learning behaviors are acquired and how they develop.

A few studies have been done comparing preschool speech and language skills and early perceptual-motor skills. Lawrence and potter (1970) found that subjects possessing functional articulation disorders showed a significantly higher degree of visual-motor integrative disability than did the control sample. The authors suggested that the study be replicated with a larger sample and with an equal number of male and female subjects, as well as a replication with subjects evidencing other kinds of expressive language disorders. No further follow-up research has been done in this area to determine the existence of concommitant visual-motor disabilities in children with articulation disorders, or syntactical disorders. Critical developmental factors within the preschool population are as yet undetermined. Since many children having specific learning disabilities are referred for speech, language and hearing services, speech and language pathologists are frequently in a position to assist in the early identification, and intervention for remediation. It is therefore necessary 
to consider major possible concommitant factors and behaviors which could relate to the language learning process.

Purpose of the Investigation

This study was designed to compare the visual-motor integrative abilities of preschool children with their articulatory and syntactical development.

The questions posed in this study were:

1. Do children having accelerated visualmotor integrative skills perform at a higher level than children having delayed visual-motor skills in their articulation proficiency?

2. Do children having accelerated visualmotor integrative skills perform at a higher level than children having delayed visual-motor skills in their syntactical ability?

Operational Definitions

The following operational definitions were used for the present investigation:

Articulation Development

The demonstrated acquisition of speech sounds in early childhood. 
Articulation Proficiency

This is to be determined by a comparison of a child's ability to the norms provided by the TemplinDarley Diagnostic Test for Articulation (Templin and Darley, 1969).

High Visual-Motor Integration Ability

Those children having scores on the Developmental Test of Visual-Motor Integration (Beery and Butenica, 1967) that were 8 months (one standard deviation) or more above their chronological age were designated as high visual-motor integration (high VMI).

Language Development

The development of the combined skills of articulation and syntax.

Learning Disability

"A specific learning disability includes such conditions as perceptual handicaps, brain injury, dyslexia, minimal brain dysfunction and developmental aphasia." "...These deficits may be exhibited in mild to severe difficulties in perception (the ability to attach meaning to sensory stimuli), conceptualization, language, memory, motor skills, or control of attention", and may be demonstrated in "an imperfect ability to listen, think, speak, read, write, spell or do mathematical calculations." *

Low Visual-Motor Integration Ability

Those children having scores on the Developmental Test of Visual-Motor Integration (Beery and Butenica, 1967) that were 8 months (one standard deviation) or more below their chronological age were designated as low visual-motor integration (low VMI).

Preschool Age

Those children who are not presently enrolled in a kindergarten program, and whose ages are between four years and four years, nine months.

*Public Law 94-142 
Syntactical Development

The development of formational patterns of phrases and sentences, the arrangement of words within the language.

Syntactical Proficiency

This will be determined through the use of the Carrow Elicited Language Inventory (CELI) (Carrow, 1974), according to the given norms.

Visual-Motor Integrative Skills

Visual-motor integration is described by Beery and Butenica (1967) as a "composite of behaviors, including visual perception and motor coordination". Visual-motor skills are divided by Beery and Butenica into: 1) visualmotor integration; 2) visual perception; 3) tracing; 4) tactile-kinesthetic sense; and 5) motor proficiency. Assessment of this skill. will be done with the Developmental Test of Visual-Motor Integration (VMI) (Beery and Butenica, 1967). 


\title{
CHAPTER II
}

\author{
REVIEW OF THE IITERATURE
}

Early Identification

Are there early indicators of specific learning disabilities that can be identified in early childhood? Can a language and/or learning disabled child be identified at preschool age as having indicators of probable learning difficulties in later academic school years?

Graf (1975), in her research as a school psychologist, found it increasingly necessary for children with learning disabilities to receive a multi-disciplinary diagnosis from medical and educational specialists. Up until the last ten to fifteen years, children with learning problems had been categorized as emotionally disturbed, mentally retarded, or sensorially impaired; none of these categories encapsulate the learning disabled. Characteristics of some of these learning disabled children overlap with such impairments, but it has become increasingly more important to view the learning disabled as a separate category. Retardation of the learning disabled in academic 
growth cannot be accounted for by any of the previous categories.

In very early studies, Eames (1950) and Schiller and Deigran (1969) saw one of the major problems confronting the field of learning disabilities to be the lack of integration and coordination of professional efforts in the areas of diagnosis and remediation. Early diagnosis was seen by Wedell (1970) as a way to reduce the possible potential effects of a learning disability by assessing the range of possible causes of a child's learning difficulties through a screening procedure to identify those skill areas which may seem to have relevance to the child's development and future academic success. Experts have differed in the reports on the incidence from 3 to 30 percent (Graf, 1975) which reflects the disagreement as to what are the critical concommitant features of a learning disability. More current reports suggest the prevalence of learning disabilities to be at 12 percent (Wallace and McLoughlin, 1979) and 10 to 16 percent (Meier, 1976). Specific criteria for a more precise identification process are as yet not completed. Review of early screening results have indicated that children's learning problems have been predictable (Eaves, Kendall, and Crichten, 1974; Maitland, Nadeau and Nadeau, 1974). Many authors propose that the child's 
skills and abilities must be analyzed, specific academic strengths and weaknesses determined, and that prescriptive teaching to the deficit areas needed to be implemented (Wolfsenberger, 1965; Feshbach, Adelman and Fuller, 1974; Keogh and Becker, 1974; and Book, 1980). Additionally, it has been presumed that with the early onset of remedial assistance, the learning disabled child will acquire the learning skills that have been identified as necessary for academic success.

In spite of the strength of the beliefs of the above researchers, recent conflicting data provided in controlled research with early diagnostic intervention demonstrated that permanent habilitative results were not obtained (Keogh and Smith, 1970; Pope, 1978; and Book, 1980). The results of the findings of Keogh and Smith (1970) and Pope (1978, cited in Book, 1980) demonstrated screening data gathered during the kindergarten year consistently predicted various types of achievement performances through the fifth grade. The results (Pope, 1978) showed that the individual student's test performance does not change significantly over the first four years. In a similar study, Book (1980) identified high-risk students at the kindergarten age level, in which he assessed academic progress through yearly group achievement tests in grades one through four. No remedial assistance was reported to 
be given. Results indicated that high risk students do not improve, but consistently lag behind in their performance when compared to low risk students. Some comparative studies have been done to analyze the instructional programs and methods used with identified high risk children. Spollen and Ballif (1971) compared high risk and normally developing kindergarten children over a one year period. Their findings indicated that the problems were not alleviated after one school year of remediation. Spollen and Ballif in the same article advanced the theory that "innate differences in developmental rate contributed to the general readiness level"; they further suggested that intervention programs should begin at an earlier age, allowing more exposure to an "organized program prior to the formal academic programming in the first grade." This would involve assessment for identification purposes to be done at a preschool age.

Screening and assessment batteries for kindergarten and preschool age levels have included a variety of skills to be assessed: general ability/intelligence tests, readiness tests, visual-motor perception (e.g., copying designs), and speech and language screening tests. The research has been directed toward identifying concommitant critical variables involved in the learning acquisition 
process. Numerous aspects of this process should be considered. Perhaps by studying the possible coexistence of certain aspects of learning, specialists may find critical features such as visual-motor perceptual skills and speech/language skills to be related closely to the learning acquisition process.

\section{Visual Perception, Visual-Motor Perception and Academic/Intellectual Development}

\section{Visual Perception}

A visual perceptual deficit is defined by Cohen (1969) as a "malfunction in the visual processing system because of organic involvement, impairment, developmental lag or lack of learning, or genetic inheritance". Throughout the literature the terms "visual perceptual" and "visualmotor perception" are frequently combined and used interchangeably. In an effort to differentiate between these skill areas, visual perception will be limited to the visual skills involving acuity and perceptual aspects that do not involve fine motor skills. Visual-motor perception will be the combination of visual perception and motor perceptual skills; this will involve the interaction of visual perception with motor executed visual tasks.

Visual perception has been researched as a possible causal factor for specific learning disabilities. It has 
been compared to scholastic achievement, reading readiness, reading ability, and eventual school success. The research findings at best are controversial. Historically, visual perception has been thought to contribute to academic failure. This assumption has been based primarily upon clinical experience and observation, and some research (Goins, 1968; Frostig and Maslow, 1973; Kephart, 1971). Several authors found supportive correlations in their studies of the relationship between visual perception, visual-motor perception and scholastic and reading achievement (Lachman, 1960; Olson, 1966; Leeds, 1971).

Conversely, many authors have concluded there is little relationship between visual perception and reading achievement levels (Cohen, 1969; Black, 1969; Sheingold, 1973; and Larsen and Hammill, 1975). Sheingold (1973) cautioned that intelligence was a variable which was not controlled for in the general research which therefore may have had a contaminating influence on the results. Additionally, Larsen and Hammill (1975), in a rather extensive review of the early literature, indicated that in the sixty studies reviewed only six authors attempted to control for intelligence. Larsen and Hammill's review focused on studies dealing with measures of academic achievement as they correlated to visual discriminations, 
spatial relations, memory, and auditory-visual integration, and the predictive relationship between visual perception and academic learning. They did a correlational study on the data collected by the previous researchers and found visual perceptual skills not to be sufficiently related to reading and academic skills. They concluded, furthermore, that "children who do poorly in school do not differ in visual perceptual ability from children who read at age expectancy". It should be noted that correlational coefficients had to meet a criterion of .35 or better to establish "predictive usefulness; the median coefficients in the comparative studies measured between .20 and .29." Cohen (1969) compared reading readiness with visual perception in disadvantaged urban subjects. He concluded that visual perception (using the Keystone Telebinocular Survey and the Frostig Developmental Test of Visual Perception for the primary students, and a constructed, and validated measure for seventh and eighth graders) have very little relationship to reading achievement level. His study used a first and second grade sample at the primary age level and an intermediate sample of seventh and eighth graders. He concluded that primary-aged, urban disadvantaged students did poorly on visual discrimination; and that there was little relationship between visual perception and reading achievement at the intermediate 
level. The implications of this study were that the seventh and eighth grade students had overcome a developmental lag in visual perception.

Sheingold's (1973) research compared visual intake capacity by age groups ranging from five year olds to adults using tachistoscopically presented items. Results indicated that initial capacity for taking in visual information was unrelated to age; however, developmental differences in visual memory were present as the task became more complex, which may have been due to the amount of processing required. She indicated that the processes of scanning, encoding and reversal, were worthy of further investigation in order to better understand the development of short-term visual memory. Park (1969) in an opthamological study reported developmental differences in ocular functions. He found that many children entering the first grade demonstrated visual immaturity, as they did not have $20 / 20$ vision according to adult standards, but by the end of the second year the incidence of low visual acuity decreased, resulting in normal vision. In the older children assessed, the lower visual acuity was almost always accompanied by a refractive error. Additionally, Park found visual functions to have a "wide range of physiological (muscle) fluctuations and imbalances 
influenced by stimuli on the sensory motor system", which suggested a functional rather than organic involvement, and emphasized the wide interplay of the various parts of the brain. In his examination of the peripheral (external) ocular mechanism, he found no significant differences between dyslexic and normal reading groups; however, in a few cases the ocular mechanism demonstrated significant functional differences between dyslexic and non-dyslexic reader groups. Approximately one-third of his dyslexic sample demonstrated electro-encephalogram ( $E E G$ ) differences and changes to be associated with the reading difficulties which related to visual attention and alertness.

From these several studies it would appear that aspects of visual (ocular) functions are developmental and that there are detectable EEG differences in a portion of the dyslexic population. Dyslexic children are not easily identified by early visual testing, but perhaps when other variables are co-investigated, a differentiation might be possible.

Visual-Motor Perception

Graubard (1966, cited in Leeds, 1971) found that the deficits in visual perception were common among children with reading difficulties, but were rarely the 
only cause of reading failure. She found that deficits in visual-motor abilities occured more frequently than within the auditory modality. She also concluded that there was a close relationship between the development of perceptual abilities and motor abilities, and concluded that the deviation in perceptual-motor development was a possible contributing factor to reading failures.

Birch and Belmont (1965) found that intersensory integrative function improved with age. In their research sample the most rapid period of development appeared to occur between five and seven years of age. This supported the research of Birch and Lefford (1963, cited in Birch and Belmont, 1965) that the most rapid period of visual-haptic, visual-kinesthetic and haptickinesthetic integrative competence occured at these early ages. It appears that during the early school ages, that highly significant changes are developing in the sensory integrative processes (involving tactile, kinesthetic, vision, and audition). Birch and Belmont (1965) advance the theory that possibly "intermodal integration is merely the prerequisite to the reading skill, whereas the intellectual competence affects the level to which the skill is acquired". Reading in these early developmental years could be more related to the 
auditory and visual integration function rather than intelligence; as the child ages, the auditory-visual integration stabilizes and is no longer as significant in the development of reading as intelligence.

Lachman (1960), in a study comparing reading ability and perceptual-motor development (using the Bender-Gestalt Test) in eight to twelve year olds in remedial reading clinics, again found implications suggesting visual-motor skills to be developmental up to eight to nine years. Poorer visual-motor ability or "distortions" were noted in the younger age group of eight to nine years. The distortions occured more frequently with the reading disability children than with normal children, but when the reading retarded and emotionally disturbed children were compared with normals, the difference fell below a statistically significant level.

In a later study, Szliwowski (1969) in critiquing the work of Bibace and Hancock (1969) also found the age level of seven to eight years to be a developmental age when many of the so-called "higher cognitive functions are just being acquired and where there is nothing pathological about (these functions) being used in a less than perfect way." 
Singer and Brunk (1967) administered a series of perceptual-motor tasks to third and fourth grade children who were rated high or low on intelligence tests to determine whether or not they would demonstrate higher or lower perceptual motor skills. There appears to be little relationship between success on the Figure Reproduction Test and intellectual ability. From the results of their study, it was hypothesized that the largest relationship between perceptual-motor variables and verbal materials appears in early childhood, and that with increasing age, achievement becomes more task specific.

Much of the research appears to imply a possible developmental factor to visual acuity, visual perception and visual-motor perception between the ages of five to nine years. This period also appears to be the cognitive developmental period. Academic assessments can be used during the early school age years of kindergarten through fourth grade to assist in the identification of learning disabilities during the early years, but during the developmental preschool years when children are developing their pre-academic skills, these tests cannot be used. Researchers must then consider the assessment of the development of motor, speech and language skills which have been developing and are 
necessary foundations for their academic success. Perhaps it is possible to find developmental language variables which would help in the early identification of language and learning disability.

Language Development,. Visual-Motor Integration and the Learning Disabled Child

In the search for co-variables between learning disabilities and speech and language disorders, researchers have compared verbal intelligence, visual perception, visual-motor perception and coordination to speech and language development. There does appear to be a corelationship between language acquisition and the learning acquisition process. Currently the literature does not agree on the variables which are co-developing and pertinent.

Verbal Cognitive Functioning

Does the cognitive, verbal functioning of a child co-develop with visual perception and visual-motor coordination? Does cognitive verbal development co-develop with reading performance? Both Weiner (1969) and Richman (1979) hypothesized that there would be a significant difference in the perceptual abilities demonstrated with children having a high performance/ low verbal profile (HP/LV) on the Wechsler Intelligence 
Scale for Children (WISC) and the normal control group. Weiner (1969) compared cognitive functioning of language deficient children with a normal control group of six to eight year olds. Language deficiency was defined as a verbal intelligence quotient (IQ) below 90 and at least a 15 point difference below the performance IQ. The control group was matched to the experimental group by performance IQ and age, but differed significantly in verbal IQ. A series of perceptual tests designed to measure the input and output modalities were administered. All subjects were post-tested one year later to validate the stability of the language deficiency criteria. The language deficient subjects demonstrated significantly weaker skills on visual tasks when combined with motor ability to copy geometric designs. Additionally, all auditory modality tasks were significantly weak. Weiner concluded that the difficulty did not rest in the visual perception of forms or in the motor area separately, but in the integration of the visual and motor systems, as in the act of copying geometric designs.

In a later study, Richman (1979) examined verbal skills of children with high performance/low verbal WISC profiles in an effort to identify sources of language impairment, and the relationship between language variables and reading achievement. Richman's results 
do not indicate that a HP/LV profile on the WISC is indicative of reading problems, as she found a significant proportion of these children read at or above grade level. Richman also found the Peabody Picture Vocabulary Test (Dunn, 1959) to yield high scores for the poorer reading groups. The Hiskey-Nebraska Test of Learning Aptitude (Hiskey) was found by Richman to provide more important information regarding reading success and expectation for the HP/LV child. This test emphasizes verbal "mediation" with skills in categorization, verbal labeling, concept formation, and memory. Richman suggested that cognitive functioning and language be further investigated to assist in the understanding of the causal factors for children with language related learning disabilities.

Results from the Weiner (1969) and Richman (1979) studies suggest that language is a variable which should be researched for possible causal factors relating to the learning process. Weiner also found visual-motor integrative skills to be weak in the HP/LV WISC profile child. It would appear then that language development and visual-motor perceptual processes could possibly be variables which relate to the learning process and quite feasibly be critical factors in the identification of a learning disability. 
Language Development and Visual-Motor Integration

In an extensive review of the literature, Wedell

(1969) found language and perceptual motor processes to be the most crucial factors relating to a child's conceptual development; he found little information available on the development of specific skills related to the learning acquisition process.

underdeveloped speech and language, and visual perception and memory of picture series were studied by Tsvetkova (1974) in an effort to determine the concommitant aspects of preschool children's speech and language development. Subjects were asked to memorize series of pictures with both verbal and non-verbal responses required. Tsvetkova concluded from the study that children with speech and language defects are also defective in visual perception and memory. She found a developmental sequence in children's speech that indicates a close relationship in visual and auditory perception, and motor reactions, and further concluded that, if there is a defect in the child's perceptual or motor processes, it will negatively affect the development and quality of speech. It should be noted that intelligence was not controlled in this study. In fact, 10 of the 50 subjects were considered mentally retarded.

Karnes, Teska, and Hodgins (1970), in their comparison of the differential effects of four preschool classroom 
models, found an interrelationship between visual-motor skills and language development. The classroom models represented a continuum of styles: traditional, communityintegration, Montessori and an experimental class which stimulated and required the appropriate verbalizations at every stage of task involvement of their motor performance. All of the groups were pre- and post-tested with the Stanford-Binet Individual Intelligence Scale (1960) and with subtests of the Illinois Test of Psycholinguistic Abilities (1961). The children in the experimental class demonstrated the greatest gains on the stanford-Binet IQ (over a 14 point mean gain) and the ITPA subtests of motor-encoding, visual-motor sequence, auditory-vocal sequence, and visual decoding. The traditional class showed modest gain, the community-integrated class showed little progress, and the Montessori class showed the least gains. It would appear from practical application of sensory or perceptual motor and verbal expression that there is some interrelationship between visual-motor skills and verbal language.

Language is described by Bloom (1980) as "the mechanism, the code, the actual shape and configuration of sounds, words and their structures". This refers to the phonological structure -- the sounds which make up our language; the morphological structure -- the smallest units of language which carry meaning; and the syntactical 
structure -- the use of words plus their word order meaningfully placed into the sentences of the language. Perhaps it is the breakdown of one of these systems that could assist in the prediction of learning difficulties. Bloom concludes from a literature review and clinical experience that the best way to understand language disorders is to study the variations of language development within the individual child who is demonstrating specific difficulty in acquiring language. In a longitudinal study of one child's vocabulary and syntactic development, she saw that his language behaviors varied from the norm, but were consistent and regular in their own pattern. This child's development was followed over a five-year period; at the age of eight he was diagnosed as having a learning disability, and was demonstrating the same difficulty in acquiring reading and writing skills as he did in the earlier years with language acquisition.

The predominant assumption in the educational literature is that there is a relationship between language disorders and learning disabilities; language is seen by many as a basis for a disability (Wedell, 1969; Wiig and Semel, 1973; Tsvetskova, 1974; and Richman, 1979). Bloom (1980) views a language disorder as a learning disability, and further proposes that language-learning disabled children have "learning- 
based language problems rather than language-based learning problems".

Regardless of which causal factor comes first, there does appear to be a relationship between the development of language skills and the acquisition of academic skills of reading and writing. There also appears to be an interrelationship between visual-motor integration and language. This relationship between language and visual-motor integration seems to be detectable at the preschool age.

Syntactical Language and Articulation

Is it possible to detect co-developing variable differences in the preschool child's speech and language development and his visual-motor coordination skills? Do the aspects of syntax and articulation of speech development co-vary?

Syntactical language development of the learning disabled child is a relatively unresearched aspect of language development. Both Wiig and Semel (1973) and Andolina (1980) compared the syntactical language of the learning disabled child to that of the normal child. Wiig and Semel (1973) compared the comprehension of linguistic concepts requiring logical syntactical operation between a control and experimental group. Their results indicated that the learning disabled child made more errors 
than the controls. The learning disabled frequently demonstrated difficulty with the sequence of critical elements and the comparative relationship involving two or more elements presented; additionally, they demonstrated more difficulty with abstraction and generalization, as well as delays in the logical development of their syntax. The authors, however, found that even though the logical grammatical structure was impaired, improvement was noted following a six week remediation program.

In a later study, Andolina (1980) compared the syntactical language and vocabulary of learning disabled and normal children. Subjects ranged from seven to thirteen years of age and were divided into four age groups. Syntactical maturity and vocabulary richness were measured after the stimulus of a silent movie; the subjects were then asked to explain the movie, and syntactical and vocabulary maturity was measured from the context of their explanation. A developmental trend was noted in both syntactical language and vocabulary. The acquisitional growth patterns of the two groups were different; the learning disabled children demonstrated gradual control of syntax and vocabulary while normal children demonstrated rapid periods of growth in the primary and intermediate grades. From the work of Wiig and Semel (1973) and Andolina (1980), it would appear 
that there are differences in the syntactical development of language between learning disabled and non-learning disabled children.

Are there also differences in the articulatory development within the learning disabled population? One study has been noted in the literature to have compared children with previously identified articulation deficiencies to visual-motor coordination skill development. Lawrence and Potter (1970) studied the possible correlation between visual-motor learning disabilities and articulation disorders in preschool and primary grade children. Children from a speech and hearing clinic having articulation problems were compared to a control group without articulation problems. The Peabody Picture Vocabulary Test (PPVT) (Dunn, 1960) was used as a screening measure of intelligence and the Developmental Test of Visual-Motor Integration (Beery and Butenica, 1967) was used to measure the degree of visual perception and motor behavior integrated. The subjects were matched according to age, race, and scores on the PPVT. Statistical analysis of their study indicated that those children having articulation defects showed a significantly higher degree of disability in visual-motor integration skills.

Review of the literature indicates that there are developmental factors in visual-motor coordination skills, 
syntactical language proficiency and articulation proficiency. Differences and delays in these areas seem to be demonstrated by children having learning difficulties and/or learning disabilities. However, no study to date has compared visual-motor coordination to articulation proficiency and syntactical language development. Are visual-motor skills co-developing with articulation proficiency? Do visual-motor skills co-develop with syntactical language? 


\section{CHAPTER III}

\section{METHODS AND PROCEDURES}

\section{Subjects}

The subjects for this investigation consisted of twenty-nine preschool children selected from one hundred and thirty-nine children who were screened from Portland area preschool and daycare centers. The subjects met the following criteria:

1. The subjects were of a preschool age, four years to four years, nine months, and were not enrolled in a kindergarten program.

2. None of the subjects had known organic motor dysfunctions nor did they wear corrective lenses.

3. A signed consent form for participation in the study was obtained for each subject (Appendix A).

4. The subjects copied geometric forms from the Developmental Test of Visual-Motor Integration and received an age score eight months (one standard deviation) or 
more above their chronological age, or eight months (one standard deviation) or more below their chronological age.

Instrumentation

Developmental Test of Visual-Motor Integration (VMI)

The Developmental Test of Visual-Motor Integration (VMI) (Beery and Butenica, 1967) consists of a series of geometric forms to be copied as a paper and pencil task. It has norms for children between the chronological ages of two to fifteen years, even though it was originally designed for preschool and early primary grades. The VMI involves only the copied reproduction of geometric forms in which the child draws the form directly from the stimulus without demonstration. No memory skills are required. The VMI can be administered in a small group or individually. Scoring criterion is well-defined in the manual. A visual-motor integration (VMI) age is established for each subject. Separate norms are provided for male and female subjects. Geometric forms have been found to be familiar to children of varying socioeconomic backgrounds.

Peabody Picture Vocabulary Test (PPVT, Form A The Peabody Picture Vocabulary Test (Dunn, 1965) is designed to provide an estimate of the subject's verbal 
intelligence based upon their receptive vocabulary. This test does not require oral responses; the subject indicates the response choice by pointing to one of four stimulus plates. There are two forms with separate test records and norms for ages two years, six months to eighteen years.

Templin-Darley Diagnostic Test for Articulation The Templin-Darley Diagnostic Test for Articulation (Templin and Darley, 1960) is designed to evaluate an individual's production of the speech units (phonemes) of the language. The complete diagnostic test includes a battery of 141 items, and itemizes articulatory data into diagnostic subgroups: consonant singles; pressure consonants; consonant clusters, vowels; and diphthongs. Standardized norms on the Templin-Darley begin at the three-year level. The age levels indicate the age by which 90 percent of the normative sample with average intelligence correctly articulate speech sounds.

\section{Carrow Elicited Language Inventory (CELI)}

The Carrow Elicited Language Inventory (Carrow, 1974) uses sentence imitation to sample a child's receptive and expressive production of grammar. It attempts to measure not only what a child produces, but also what he is capable of producing through the use of items which represent a 
wide range of grammatical complexity. The grammatical categories covered by the test are: articles, adjectives, nouns, noun plurals, pronouns, verbs, negatives, contractions, adverbs, prepositions, demonstratives and conjunctions. There are additionally five categories of error types: substitutions, omissions, additions, transpositions, and reversals. Percentile ranks and standardized stanine scores correspond to specific raw scores, and are applicable to children between the ages of three years and seven years, eleven months.

\section{Procedures}

The study proceeded in two experimental stages. The testing on each subject was completed within a one month period or less. During the first stage the subjects were screened for differences in visual-motor coordination skills with the VMI. This test was administered in small groups of two to four, and occasionally, individually. These sessions took approximately five minutes. After the VMI screening, twenty-nine children were selected as having age scores of eight months or more above their chronological age, or eight months or more below their chronological age. Fourteen subjects were designated as having "high visual motor integration" (high VMI) and fifteen subjects were designated as having "low visual motor integration" (low VMI). 
In the second stage, the twenty-nine subjects chosen for further assessment were tested with the PPVT, the CELI, and the Templin-Darley Test for Articulation. The PPVT was used to screen out those children who were below a certain mental age based upon their receptive vocabulary ability. All subjects met a criteria of 90 or above on the intelligence quotient measured on the PPVT. All scores on the PPVT ranged between 90 and 118 with a mean of 104 . Continuing in the second testing session, articulation proficiency and syntactical production were assessed. In the second session of testing each child participated for 20 to 30 minutes. The Templin-Darley Diagnostic Test for Articulation was given using the picture stimulus, and verbal stimulation/repetition as needed. The administration of this test took approximately ten minutes, and the scoring was done during the test time. The Carrow Elicited Language Inventory which uses sentence imitation was recorded on audio tape to limit the length of the test session, without on-site scoring and to ensure scoring validity. The administration of this test took approximately five to ten minutes. The scoring was done after the test was completed.

Statistical Analysis of Data

After the articulation testing and the language testing, the subjects demonstrating "high visual-motor 
integrative skills" and those demonstrating "low visualmotor integrative skills" were compared according to their articulation proficiencies, and their syntactical language abilities. Those children who scored eight months or more above their chronological age on their test of visual-motor integration were designated as "high visual-motor integrative". (HVMI) skilled; and those children who scored eight months or more below their chronological age were designated as "low visual-motor integrative". (LVMI) skilled.

Two one-tailed $\underline{t}$-tests for independent measures were computed to assess the significance of different performance levels of the high and low visual-motor integration groups with respect to articulation and syntactic language abilities, respectively. In addition, it was determined that a statistic that is insensitive to the effect of extreme scorers would provide additional information for this data analysis. Therefore, two Chi square statistics were computed from two tables, one each for the articulation and the syntactic data. Median scores were used to divide high scorers from low scorers on the dependent variables. 


\title{
CHAPTER IV
}

\section{RESULTS AND DISCUSSION}

\author{
Results
}

The purpose of this study was to compare visualmotor integrative (VMI) abilities of preschool children (ages 4 years, 0 months to 4 years, 9 months) with their articulatory and syntactical development. The questions posed in this study were:

1. Do children having accelerated visualmotor integrative skills perform at a higher level than children having delayed visualmotor skills in their articulation proficiency?

Articulation proficiency was measured by the Templin-Darley Diagnostic Test for Articulation: The error scores of the high visual-motor integrative children were compared to the error scores of the low visual-motor integrative children using a one-tailed t-test for independent measures to determine if there is a significant difference in performance between the two groups. The means and standard deviations of error scores were calculated for each group (Table I). When the low VMI children were compared to the high VMI children, a $t$ value of $.61($ d.f. $=27)$ was found, which was not statistically 
significant at the .05 level. A significant difference in visual-motor integration and articulation proficiency was not demonstrated.

\section{TABLE I}

COMPARISON OF RAW SCORES ON TEMPLIN-DARLEY DIAGNOSTIC TEST FOR ARTICULATION SHOWING MEANS, STANDARD DEVIATIONS, AND $t$-SCORE VALUES FOR LOW VISUAL-MOTOR INTEGRATION (VMI) AND HIGH VISUAL-MOTOR INTEGRATION (VMI) GROUPS

Test Group

Mean

Raw Score

Standard

Deviation $\underline{t}$-Score Value

\section{LOW VMI}

32.86

24.22

High VMI

27.07

26.41

$\mathrm{p}>.05$

$\mathrm{N}=29$

Due to the small sample used $(\mathrm{N}=29)$, and consequent high sensitivity of group distributions to extreme scorers, further computation was done using the chi square $\left(x^{2}\right)$ statistic. The analysis demonstrated differences in the predicted direction (Table II), but fell short of statistical significance, with $x^{2}=.8356($ d.f. $=1)$. This analysis further verifies that there is not a significantly higher performance on articulation proficiency by high VMI individuals when score extremity is not a factor. No evidence supporting a significant difference 
in high visual-motor integration skills and level of articulation proficiency was found.

TABLE II

GROUP DISTRIBUTION OF SCORES ON

TEMPLIN-DARLEY TEST FOR ARTICULATION

USING CHI-SQUARE ANALYSIS

$\left.\begin{array}{|l|c|c|c|}\hline \begin{array}{l}\text { Error Scores on } \\ \text { Templin-Darley Artic. }\end{array} & \text { Low VMI } & \text { High VMI } & \text { TOTAL } \\ \hline \text { Fewer Error Scores } \\ \begin{array}{l}\text { Greater Error Scores } \\ \text { TOTAL }\end{array}\end{array}\right)$

$x^{2}=.8356, p>.05(d . f .=1)$

2. Do children having accelerated visual-motor integrative skills perform at a higher level than children having delayed visual-motor integrative skills in their syntactical language ability?

Syntactical language ability was measured by the Carrow Elicited Language Inventory (CELI). The syntactical error scores on the CELI of the high visual-motor integrative children were compared to the syntactical error scores of the low visual-motor integrative children using a one-tailed $\underline{t}$-test for independent measures to determine if there was a significant difference in the performance of the two groups. The means and the standard deviations 
were calculated for both groups (Table III). When the high VMI children were compared to the low VMI children, a $t$ value of $1.85(d . f .=27)$ was found, which was statistically significant $(p<.05)$. This supports the hypothesis that high visual-motor integrative ability preschool children perform with higher syntactical language ability.

TABLE III

COMPARISON OF RAW SCORES ON THE CELI, SHOWING MEANS, STANDARD DEVIATIONS, AND t-SCORE VALUES FOR LOW VISUAL-MOTOR INTEGRATION (VMI) AND HIGH VISUAL-MOTOR INTEGRATION (VMI) GROUPS

\begin{tabular}{lccc}
\hline Test Group & $\begin{array}{c}\text { Mean } \\
\text { Raw Score }\end{array}$ & $\begin{array}{c}\text { Standard } \\
\text { Deviation }\end{array}$ & t-Score Value \\
\hline Low VMI & 25.20 & 8.71 & $t=1.85$ \\
High VMI & 19.57 & 7.52 & $\underline{t}=$ \\
\hline
\end{tabular}

$* \mathrm{p}<.05$

Visual inspection of the data clearly indicated the presence of extreme scores in this small sample. Therefore, it was desirable to analyze the data with a statistic that was not sensitive to score extremity and a chi square $\left(x^{2}\right)$ was computed. When the $x^{2}$ analysis was performed, a 
disproportionately low number of high scores on the CELI and high VMI were found. The differences within the entire sample were not in the predictable directions. The value of $x^{2}$ was $.3878(d . f .=1)$, failing statistical significance at the .05 level of confidence. On the basis of this follow-up data analysis, there is not supporting evidence that children with higher visual-motor integrative skills also demonstrate high syntactical language abilities (Table IV).

\section{TABLE IV}

GROUP DISTRIBUTION OF SCORES ON CARROW ELICITED LANGUAGE INVENTORY (CELI) USING CHI SQUARE ANALYSIS

\begin{tabular}{|l|c|c|c|}
\hline Scores on CELI & LOW VMI Group & High VMI Group & TOTAL \\
\hline $\begin{array}{l}\text { Fewer Error } \\
\text { Scores } \\
\begin{array}{l}\text { Greater Error } \\
\text { Scores }\end{array}\end{array}$ & 8 & 5 & 13 \\
\hline TOTAL & 8 & 8 & 16 \\
\hline
\end{tabular}

$x^{2}=.3878, p>.05(d . f .=1)$

\section{Discussion of Results}

The second question in this study dealt with the experimental comparison of visual-motor integrative 
abilities and syntactical language abilities. The data in this study were analyzed by a one-tailed $\underline{t}$-test, and was found to be marginally significant. However, according to Guilford (1956), "If there is good reason to believe that if the population distribution is not normal but is seriously skewed, and especially if the samples are small, the $\underline{t}$-test does not apply." Further computation was done with the Chi square statistic, which is insensitive to the effects of extreme high or low scores. Using the additional Chi Square Analysis as a follow-up procedure, supporting evidence is not given that children with higher visual-motor integrative abilities also demonstrate higher syntactical language abilities.

It appears to this investigator that several factors could have contributed to the above results. First, there may have been a selection bias, initially, as all subjects in this study were required to have a signed parental permission slip. This may have excluded subjects who would have normally been included in a random sampling. The sample size $(\mathrm{N}=29)$ was also small, and was possibly not representative of a random population sample.

Secondly, the initial qualifying criterion of one standard deviation (eight months deviation from chronological age) difference on the Beery VMI was possibly 
not an adequate criterion; perhaps the subjects were not extreme enough in their visual-motor integration differences, and the qualifying criterion needed to be greater than a one standard deviation difference.

Third, current research findings (Wallace and McLoughlin, 1979) indicate that from a normal population sample, only 12 percent of school age children are considered learning disabled. Perhaps then out of the total study sample, only a few subjects could be expected to demonstrate this agreement. Table V displays the individual subject's VMI score deviations from chronological age by number of months, and the CELI test error scores. Two subjects (LVMI-14 and LVMI-15) demonstrate VMI scores beyond two standard deviations; these subjects also demonstrated high error scores on the syntactical testing with the CELI. The high VMI subjects' scores are displayed in this discussion but no subject was two standard deviations above his chronological age in visual-motor intergration skills. Complete tables of all data collected are displayed in the appendices.

It would seem from these data that a correlation between low visual-motor integration skills and low syntactical language skills does not exist at the preschool age level. If there is a significance, it 





would be demonstrated in the extreme scores which fall below two standard deviations.

In response to the first question, the data from this experimental comparison of visual-motor integrative abilities and articulation proficiencies indicate there is not a significant difference when visual-motor integrative skills are used as qualifying criteria for early identification of learning disabilities. Several factors could have contributed to these results. First, perhaps it should be considered that visual-motor integration not be used as an initial qualifying criterion measure as a possible indicator for learning disabilities prior to the academic experience. Second, the initial qualifying criteria of one standard deviation leight months in chronological age) on the VMI was inadequate, and the severity of the subjects was insufficient to designate a significant difference in visual-motor skills. However, a study done prior to this (Lawrence and Potter, 1970) compared children previously diagnosed as deficient in articulation skills and found them to demonstrate a significantly higher degree of disability in visualmotor integration skills. It should be considered that fine motor, VMI skills are possibly not the primary deficit skill area to initially identify. Children with previously identified articulation disorders would perhaps better exemplify any correlation between 
articulation skill and fine motor skill development.

Finally, perhaps there is a methodological issue present here. Two statistical measures were used in the analysis. If the present study had stopped with the t-test, the conclusion on the statistical significance of the correlation between syntactical language and visual-motor integrative skills would have been misleading. This study might be seen as a caution to investigators dealing with this or other related areas where individual differences are large and the sample sizes are small. It would be advisable in these cases to perform follow-up non-parametric tests that are not sensitive to the effect which extreme high or low scores have on $\underline{t}$-tests and other parametric data analysis. 


\section{CHAPTER. V}

\section{SUMMARY AND IMPLICATIONS}

\section{Summary}

The purpose of this study was to compare the visualmotor integrative abilities of preschool children with their articulatory and syntactical development. Two questions were posed: Do children having accelerated visual-motor integrative skills perform at a higher level than children having delayed visual-motor integration skills in 1) their articulation proficiency, and 2) their syntactical abilities?

Twenty-nine preschool children were selected from Portland area preschool and daycare centers on the basis of age, parental permission for participation, lack of known organic involvement, and ability to copy geometric designs. Each subject was evaluated with the Developmental Test of Visual-Motor Integration and had received a score one standard deviation, or more, above or below their chronological age. All subjects met a criterion of 90 or above on the intelligence quotient on the peabody Picture Vocabulary Test. Each child was then given the Templin-Darley Diagnostic Test for Articulation, and the 
Carrow Elicited Language Inventory to determine their skill levels.

After the articulation testing and the language testing, the subjects demonstrating "high visual-motor integration", and those demonstrating "low visual-motor integration" were compared according to their articulation proficiencies and their syntactical language abilities. Two statistical measures of one-tailed t-tests for independent measures, and Chi square analysis were computed to determine the significance of the high (HVMI) and low (LVMI) visual-motor integration groups with respect to articulation and syntactic language abilities. Results of the t-tests indicated that there was not a statistical difference between articulation skills of the HVMI and LVMI group, and that there was a marginal significance between syntax and visual-motor integration. Further analysis demonstrated an "error" in the $\underline{t}$-test significance; this significance appeared to be an artifact of extreme scores on a small sample. From examination of the data in this study it was concluded: 1) there was no significant difference between visual-motor integration and articulation skills when preschool children were identified by their fine motor skills; and 2) there was no significant difference between visual-motor integration and syntactical language 
skills when preschool children were identified by their fine motor skills.

\section{Research Implications}

In this study the majority of the subjects who were finally selected fell within one two standard deviations from their chronological age in the visual-motor integrative skills. Future research should definitely use a larger population sample with an increased severity on the Developmental Test of Visual-Motor Integration; a sample demonstrating a more significant difference (two standard deviations, and beyond) should be considered. It also could be considered to compare only the visual development of the preschooler to speech and language development, which would eliminate the variable of fine motor development.

Another study might be conducted using a larger sample who had been previously identified as speech and language handicapped, which then would have the independent variable be the visual-motor integration skills. This population could include primarily preschoolers, or could be expanded to include a range of different developmental ages.

Finally, it would seem that the Developmental Test of Visual-Motor Integration is perhaps not one of the 
better indicators of early learning disabilities to be used as an initial screening tool. It would be recommended by this investigator that the Developmental Test of Visual-Motor Integration be used only as a part of a screening battery, and not as the initial screening. It would appear that perhaps components of speech and language development would be better indicators of the skills that the preschooler brings to the beginning school situation. 


\section{BIBLIOGRAPHY}

ANDOLINA, C. Syntactic maturity and vocabulary richness of learning disabled children at four age levels. Journal of Learning Disabilities, $1980,13,372-377$.

BEERY, K.E. and BUTENICA, N.A. Developmental Test of Visual Motor Integration. Chicago, Illinois: Follett Publishing Company, 1967.

BIBACE, R. and HANCOCK, K. Relationships between perceptual and conceptual processes. Journal of Learning Disabilities, 1969, 2, 17-22.

BIRCH, H.G. and BELMONT, L. Auditory-visual integration, intelligence and reading ability in school children. Perceptual Motor Skills, 1965, 20, 294-304.

BLACK, F.W. Achievement test performance of high and low perceiving learning disabled children, Academic Therapy Quarterly, 1969, 5, 119-127.

BLOQM, L. Language development, language disorders and learning disabilities: LD3. Bulletin of orton Society, 1980, 30, 115-130.

BLOOM, L. and LAHEY, M. Language Development and Language Disorders. New York, N.Y.: John Wiley and Sons, Inc., 1978.

BOOK, R. Identification of educationally at risk children during the kindergarten year: a four year follow-up. Psychology in the Schools, 1980, 17, 153-158.

CARROW, E. Carrow Elicited Language Inventory. Austin, Texas: Learning Concepts, Inc., 1974.

COHEN, S.A. Studies in visual perception and reading in disadvantaged children. Journal of Learning Disabilities, 1969,2 .

DUNN, L.M. Peabody Picture Vocabulary Test. Minneapolis, Minn.: American Guidance Service, 1959.

EAMES, T.H. The relationships of reading and speech difficulties, Journal of Education Psychology, $1950,41,51-5 \overline{5}$. 
EAVES, L.C., KENDALL, D.C., and CRICHTON, J.U. Early identification of learning disabilities: a follow-up study. Journal of Learning Disabilities, $1974,7,632-638$.

FESHBACH, S., ADELMAN, H. and FULLER, W.W. Early identification of children with high risk of learning failure. Journal of Learning Disabilities, $1974,7,639-644$.

FROSTIG, M. and MASLOW, P. Learning Problems in the Classroom. New York, N.Y.: Grune and stratton, 1973.

GOINS, J.T. Visual Perceptual Abilities and the Early Reading Process. Chicago, Illinois: University of Chicago Press, 1968.

GRAF, M. A school psychologist's perceptions of learning disabilities in three-year old children in an early childhood education center. Paper presented at the Illinois Council for Exceptional Children, Chicago, Illinois, 1975.

GRAUBARD, P.S. Psycholinguistic correlates of reading disability in disturbed children, paper presented at American Psychological Association meeting, New York, 1966. Cited by Leeds, Physical factors in reading. Journal of Reading Specialists, 1971, $11,71-86$.

GUILFORD, J.P. Fundamental Statistics in Psychology and Education. New York, N.Y.: McGraw-Hill Book Co., 1956.

KARNES, M.B., TESKA, J.A., and HODGINS, A.S. The effects of four programs of classroom intervention on the intellectual and language development of 4-year old disadvantaged children. American Journal of Orthopsychiatry, $1970,40,58-76$.

KEOGH, B.K. and BECKER, L. Early detection of learning problems: questions, cautions and guidelines. Exceptional Children, 1974, 40, 5-11.

KEOGH, B.K. and SMITH, C. Early identification of educationally high potential and high risk children. Journal of School Psychology, 1970, $8,285-290$. 
KEPHART, N.C. The slow Learner in the Classroom, Second Edition. Columbus, Ohio: Charles E. Merrill Publishing Company, 1971.

LACHMAN, F.M. Perceptual-motor development in children retarded in reading development. Journal of Consulting Psychology, 1960, 24, 427-431.

LARSEN, S.C. and HAMMILL, D.D. The relationship of selected visual-perceptual abilities to schoollearning. Journal of Special Education, 1975, $9,281-291$.

LAWRENCE, D.B. and POTTER, R.E. Visual-motor disabilities in children with functional articulation defects. Journal of Learning Disabilities, 1970, 3, 17-20.

LEEDS, D.S. Physical factors in reading disabilities. Journal of Reading Specialists, 1971, 11, 71-86.

MAITLAND, S.J., NADEAU, B.E. and NADEAU, G. Early school screening practices. Journal of Learning Disabilities, $1974,7,55-59$.

MEIER, J.H. Development and Learning Disabilities: Evaluation, Management, and Prevention in Children. Baltimore, Maryland: University Park Press, 1976.

OLSON, A.V. School achievement, reading ability and specific visual perceptual skills. Reading Teacher, 1966, 19, 490-492.

PARK, G.E. Opthamological aspects of learning disabilities, Journal of Learning Disabilities, $1969,2,14-23$.

POPE, J.G. Kindergarten screening project: a fiveyear follow-up study. Paper presented at the Tenth Annual Convention of the National Association of School Psychologists, New York, 1978. Cited in BOOK, R.M., Identification of educationally at risk children during the kindergarten year, Psychology in the Schools, $1978,17,153-158$. 
RICHMAN, L. Language variables relating to reading ability of children with verbal deficits. Psychology in the Schools, 1979, 16, 299-305.

RYCKMAN, D.B. and RENTFROW, R.K. The Beery developmental test of visual-motor intergration: an investigation of reliability. Journal of Learning Disabilities, $1971,4,333-334$.

SCHILLER, J.J. and DEIGRAN, M.C. An approach to diagnosis and remediation of learning disabilities. Journal of Learning Disabilities, 1969, 2, 308-319.

SHEINGOLD, K. Developmental differences in intake and storage of visual information. Journal of Experimental Child Psychology, 1973, 16, 1-11.

SINGER, R.N. and BRUNK, J.W. Relation of perceptualmotor ability and intellectual ability in elementary school children. Perceptual and Motor Skills, 1967, 24, 967-970.

SPOLLEN, J.C. and BALLIF, B.L. Effectiveness of individualized instruction for kindergarten children with a developmental lag. Exceptional Child, 1971, 38, 205-209.

SZLIWOWSKI, H.B. Critique from open forum on: relationships between perceptual and conceptual cognitive processes. Journal of Learning Disabilities, 1969, 1, 21-22.

TEMPLIN, M.C. and DARLEY, F.L. The Templin-Darley Tests of Articulation. Iowa City, Iowa: Bureau of Education Research and Service, University of Iowa, 1969.

TSVETKOVA, L.S. A consideration of basic approaches to diagnosis of children with speech defects. Journal of Special Education, 1974, 8, 179-188.

WALLACE, G. and MCLOUGHLIN, J.A. Learning Disabilities: Concepts and Characteristics. Columbus, Ohio: Charles E. Merrill Publishing Company, 1979.

WEDELL, K. Critique of relationships between perceptual and conceptual cognitive processes. Journal of Learning Disabilities, 1969, 2, 25-26. 
WEDELL, K. Diagnosing learning difficulties: a sequential strategy. Journal of Learning Disabilities, 1970, $3,15-21$.

WEINER, P.S. The cognitive functioning of language deficient children. Journal of Speech and Hearing Research, 1969, 12, 53-54.

WIIG, E. and SEMEL, E. Comprehension of linguistic concepts requiring logical operations by learning disabled children. Journal of Speech and Hearing Research, 1973, 16, 627-636.

WOLFSENBERGER, W. Diagnosis diagnosed. Journal of Mental Subnormality, $1965,11,62-70$.

Definition of "specific learning disabilities" taken from Public Law 94-142, The Education for All Handicapped Children Act, 1975 (20 U.S.C. 1400), preceded by No. 504, Rehabilitation Act of 1973 (29-U.S.C. 706). Updated regulations issued to implement the law were printed in Vol. 42, No. 153 of the Federal Register. Washington, D.C.: August 23,1977 . 
APPENDIX A

PARENTAL PERMISSION

Dear Parents,

I am a speech therapist in the Portland schools and will be conducting a research project for completion of a Masters degree through Portland State University. I will be observing fine-motor coordination skills, and speech and language development in four-year olds.

I would like to see children between the ages of four years and four years, nine months in my study. This study would take 15 minutes of your child's time to copy geometric shapes or designs. Some children would be requested to return for a second testing session, which would assess speech sound, grammar, and vocabulary skills. This second testing session would take approximately 45 minutes. Of those children selected for the second session, any problems noted in speech and/or language development could be shared with you and the preschool if you so desire. Confidentiality will be maintained in the study; no names will appear in the study, only the overall results will be used. All children will be tested within the setting of their preschool or day care center.

Tests: to be administered:

First Session: Developmental Test of Visual-Motor Integration

Second Session: Peabody Picture Vocabulary Test Templin-Darley Screening and Diagnostic Test of Articulation Carrow Elicited Language Inventory

If you consent to your child's participation in this study, please sign the consent form below.

Sincerely yours,

Andrea Perry Graham

Speech and Language Therapist

I give my consent for my child

(birthdate) to be included in the speech and

language study conducted by Andrea Graham at my child's day care center. 
APPENDIX A

\section{PARENT PERMISSION RECORD}

I give my consent for my child to participate in the speech and language study conducted by Andrea Graham at my child's preschool or day care center.

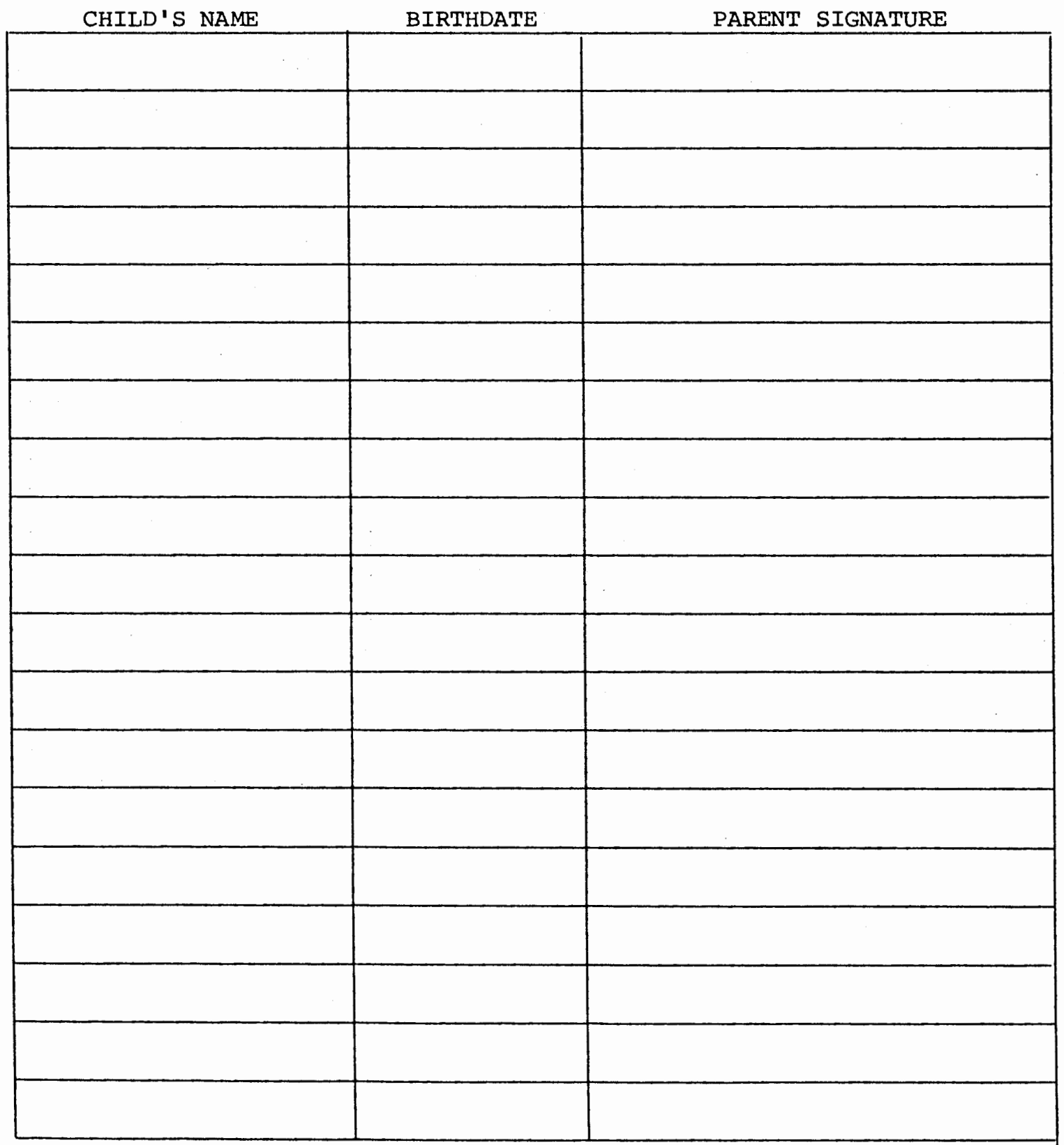




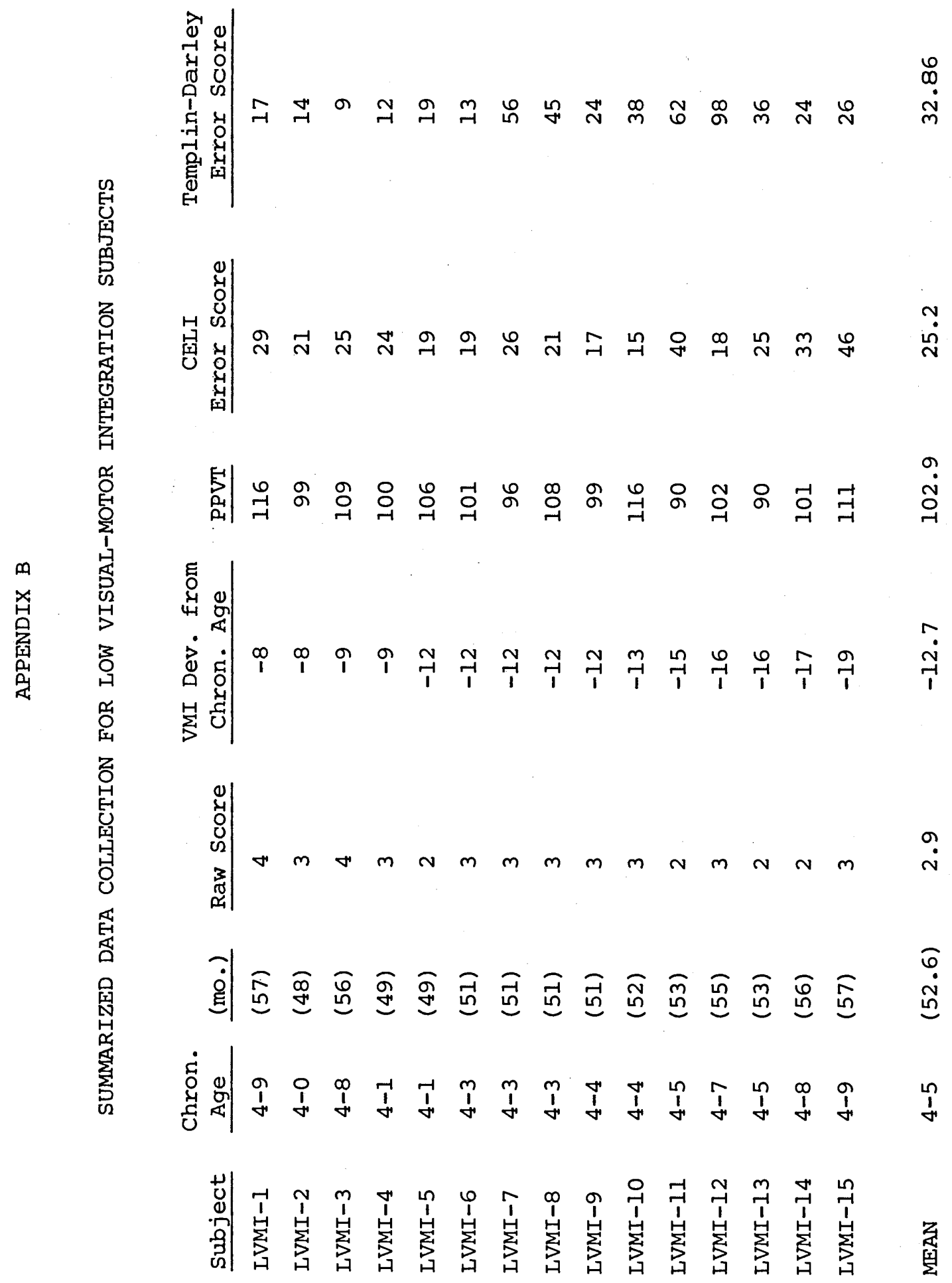









\section{APPENDIX D}

COMPARISON OF LOW VISUAL-MOTOR INTEGRATION (LVMI)

DEVIATIONS AND TEMPLIN-DARLEY ARTICULATION TEST ERROR SCORES

\begin{tabular}{|c|c|c|c|c|c|c|}
\hline Subject & $\begin{array}{l}\text { Chron. } \\
\text { Age }\end{array}$ & (mo.) & $\begin{array}{c}\text { VMI } \\
\text { Raw Score } \\
\end{array}$ & $\begin{array}{l}\text { VMI } \\
\text { Dev. }\end{array}$ & PPVT & $\begin{array}{c}\text { Templin-Darley } \\
\text { Error Score }\end{array}$ \\
\hline LVMI-1 & $4-9$ & (57) & 4 & -8 & 116 & 17 \\
\hline LVMI-2 & $4-0$ & $(48)$ & 3 & -8 & 99 & 14 \\
\hline LVMI-3 & $4-8$ & (56) & 4 & -9 & 109 & 9 \\
\hline LVMI -4 & $4-1$ & (49) & 3 & -9 & 100 & 12 \\
\hline LVMI -5 & $4-1$ & (49) & 2 & -12 & 106 & 19 \\
\hline LVMI-6 & $4-3$ & (51) & 3 & -12 & 101 & 13 \\
\hline LVMI-7 & $4-3$ & (51) & 3 & -12 & 96 & 56 \\
\hline LVMI-8 & $4-3$ & (51) & 3 & -12 & 108 & 45 \\
\hline LVMI-9 & $4-4$ & (51) & 3 & -12 & 99 & 24 \\
\hline LVMI-10 & $4-4$ & (52) & 3 & -13 & 116 & 38 \\
\hline LVMI-II & $4-5$ & (53) & 2 & -15 & 90 & 62 \\
\hline LVMI -12 & $4-7$ & (55) & 3 & -16 & 102 & 98 \\
\hline LVMI-13 & $4-5$ & (53) & 2 & -16 & 90 & 36 \\
\hline LVMI-14 & $4-8$ & (56) & 2 & -17 & 101 & 24 \\
\hline LVMI-15 & $4-9$ & (57) & 3 & -19 & 111 & 26 \\
\hline MEAN & $4-5$ & & 2.9 & -12.7 & 102.9 & 32.86 \\
\hline
\end{tabular}


APPENDIX E

COMPARISON OF HIGH VISUAL-MOTOR INTEGRATION (HVMI)

DEVIATIONS AND TEMPLIN-DARLEY ARTICULATION TEST ERROR SCORES

\begin{tabular}{|c|c|c|c|c|c|c|}
\hline Subject & $\begin{array}{l}\text { Chron. } \\
\text { Age } \\
\end{array}$ & (mo.) & $\begin{array}{c}\text { VMI } \\
\text { Raw Score } \\
\end{array}$ & $\begin{array}{l}\text { VMI } \\
\text { Dev. }\end{array}$ & PPVT & $\begin{array}{c}\text { Templin-Darley } \\
\text { Error Score }\end{array}$ \\
\hline HVMI-1 & $4-4$ & $(52)$ & 8 & +8 & 108 & 11 \\
\hline HVMI-2 & $4-8$ & (56) & 9 & +8 & 108 & 8 \\
\hline HVMI-3 & $4-8$ & $(56)$ & 9 & +8 & 118 & 40 \\
\hline HVMI-4 & $4-3$ & (51) & 8 & +8 & 102 & 43 \\
\hline HVMI - 5 & $4-5$ & (53) & 9 & +8 & 113 & 2 \\
\hline HVMI-6 & $4-4$ & $(52)$ & 9 & +12 & 101 & 88 \\
\hline HVMI-7 & $4-9$ & $(57)$ & 10 & +9 & 114 & 21 \\
\hline HVMI-8 & $4-4$ & $(52)$ & 8 & +9 & 104 & 4 \\
\hline HVMI-9 & $4-6$ & (54) & 9 & +10 & 94 & 64 \\
\hline HVMI-10 & $4-5$ & (53) & 9 & +10 & 106 & 9 \\
\hline HVMI-11 & $4-8$ & $(56)$ & 10 & +10 & 108 & 6 \\
\hline HVMI- 12 & $4-6$ & $(54)$ & 9 & +10 & 104 & 53 \\
\hline HVMI-13 & $4-5$ & (53) & 9 & +11 & 101 & 18 \\
\hline HVMI-14 & $4-9$ & $(57)$ & 10 & +11 & 101 & 12 \\
\hline MEAN & $4-6$ & (54) & 9 & +9.4 & 105.1 & 27.07 \\
\hline
\end{tabular}


COMPARISON OF LOW VISUAL-MOTOR INTEGRATION (LVMI)

DEVIATIONS AND CARROW ELICITED LANGUAGE

INVENTORY (CELI) ERROR SCORES

\begin{tabular}{|c|c|c|c|c|c|c|}
\hline Subject & $\begin{array}{l}\text { Chron. } \\
\text { Age } \\
\end{array}$ & (mo.) & $\begin{array}{c}\text { VMI } \\
\text { Raw Score } \\
\end{array}$ & $\begin{array}{l}\text { VMI } \\
\text { Dev. }\end{array}$ & PPVT & CELI \\
\hline IVMI-1 & $4-9$ & $(57)$ & 4 & -8 & 116 & 29 \\
\hline LVMI-2 & $4-0$ & $(48)$ & 3 & -8 & 99 & 21 \\
\hline LVMI-3 & $4-8$ & $(56)$ & 4 & -9 & 109 & 25 \\
\hline IVMI-4 & $4-1$ & (49) & 3 & -9 & 100 & 24 \\
\hline IVMI -5 & $4-1$ & $(49)$ & 2 & -12 & 106 & 19 \\
\hline LVMI-6 & $4-3$ & (51) & 3 & -12 & 101 & 19 \\
\hline IVMI-7 & $4-3$ & (51) & 3 & -12 & 96 & 26 \\
\hline LVMI-8 & $4-3$ & (51) & 3 & -12 & 108 & 21 \\
\hline LVMI-9 & $4-4$ & (51) & 3 & -12 & 99 & 17 \\
\hline LVMI-10 & $4-4$ & $(52)$ & 3 & -13 & 116 & 15 \\
\hline LVMI-II & $4-5$ & $(53)$ & 2 & -15 & 90 & 40 \\
\hline LVMI-12 & $4-7$ & $(55)$ & 3 & -16 & 102 & 18 \\
\hline LVMI-13 & $4-5$ & $(53)$ & 2 & -16 & 90 & 25 \\
\hline LVMI-14 & $4-8$ & $(56)$ & 2 & -17 & 101 & 33 \\
\hline LVMI-15 & $4-9$ & (57) & 3 & -19 & 111 & 46 \\
\hline MEAN & $4-5$ & $(52.6)$ & 2.9 & -12.7 & 102.9 & 2 \\
\hline
\end{tabular}


APPENDIX G

COMPARISON OF HIGH VISUAL-MOTOR INTEGRATION (HVMI) DEVIATIONS AND CARROW ELICITED IANGUAGE INVENTORY (CELI) ERROR SCORES

\begin{tabular}{|c|c|c|c|c|c|c|}
\hline Subject & $\begin{array}{l}\text { Chron. } \\
\text { Age } \\
\end{array}$ & (mo.) & $\begin{array}{c}\text { VMI } \\
\text { Raw Score } \\
\end{array}$ & $\begin{array}{l}\text { VMI } \\
\text { Dev. }\end{array}$ & $\underline{\text { PPVT }}$ & CELI \\
\hline HVMI-1 & $4-4$ & $(52)$ & 8 & +8 & 108 & 27 \\
\hline HVMI-2 & $4-8$ & $(56)$ & 9 & +8 & 108 & 33 \\
\hline HVMI-3 & $4-8$ & $(56)$ & 9 & +8 & 118 & 21 \\
\hline HVMI-4 & $4-3$ & (51) & 8 & +8 & 102 & 29 \\
\hline HVMI -5 & $4-5$ & (53) & 9 & +8 & 113 & 11 \\
\hline HVMI- 6 & $4-4$ & $(52)$ & 9 & +12 & 101 & 19 \\
\hline HVMI-7 & $4-9$ & $(57)$ & 10 & +9 & 114 & 17 \\
\hline HVMI-8 & $4-4$ & $(52)$ & 8 & +9 & 104 & 10 \\
\hline HVMI-9 & $4-6$ & (54) & 9 & +10 & 94 & 27 \\
\hline HVMI-10 & $4-5$ & (53) & 9 & +10 & 106 & 19 \\
\hline HVMI-11 & $4-8$ & $(56)$ & 10 & +10 & 108 & 14 \\
\hline HVMI-12 & $4-6$ & (54) & 9 & +10 & 104 & 24 \\
\hline HVMI-13 & $4-5$ & (53) & 9 & +11 & 101 & 11 \\
\hline HVMI-14 & $4-9$ & (57) & 10 & +11 & 101 & 12 \\
\hline MEAN & $4-6$ & (54) & 9 & 9.4 & 105.8 & 1 \\
\hline
\end{tabular}




\section{APPENDIX $\mathrm{H}$}

TOTAL SCORES FROM

LOW VISUAL-MOTOR INTEGRATION SUBJECTS (LVMI)

ON CARROW ELICITED LANGUAGE INVENTORY (CEII)

\begin{tabular}{|c|c|c|c|c|c|c|}
\hline \multirow[b]{2}{*}{ Subject } & \multirow[b]{2}{*}{ Sex } & \multirow{2}{*}{$\begin{array}{l}\text { Age } \\
\text { (mo.) }\end{array}$} & \multirow{2}{*}{$\begin{array}{l}\text { VMI } \\
\text { Dev. }\end{array}$} & \multicolumn{3}{|c|}{ TOTAL SCORE } \\
\hline & & & & Raw Score & Percentile & Stanine \\
\hline LVMI-1 & M & 57 & 4 & 29 & 33.6 & 4 \\
\hline LVMI-2 & $\mathrm{F}$ & 48 & 3 & 21 & 54.1 & 5 \\
\hline LVMI-3 & $\mathrm{F}$ & 56 & 4 & 25 & 41.0 & 5 \\
\hline LVMI-4 & $\mathrm{F}$ & 49 & 3 & 24 & 42.6 & 5 \\
\hline LVMI-5 & M & 49 & 2 & 19 & 59.8 & 6 \\
\hline LVMI-6 & $F$ & 51 & 3 & 19 & 59.8 & 6 \\
\hline LVMI-7 & $\mathrm{F}$ & 51 & 3 & 21 & 54.1 & 5 \\
\hline LVMI-8 & M & 51 & 3 & 18 & 61.5 & 6 \\
\hline LVMI -9 & $\mathrm{F}$ & 52 & 3 & 15 & 68.9 & 6 \\
\hline LVMI-10 & M & 53 & 2 & 40 & 15.6 & 3 \\
\hline LVMI-1I & $\mathrm{F}$ & 55 & 3 & 18 & 61.5 & 6 \\
\hline LVMI -12 & M & 53 & 2 & 25 & 41.0 & 5 \\
\hline LVMI-13 & M & 56 & 2 & 33 & 25.4 & 4 \\
\hline LVMI-14 & M & 57 & 2 & 46 & 10.7 & 3 \\
\hline LVMI -15 & F & 51 & 3 & 26 & 38.5 & 5 \\
\hline MEAN & & 52.6 & 2.9 & 25.2 & & 4.9 \\
\hline
\end{tabular}




\section{APPENDIX I}

TOTAL SCORES FROM

HIGH VISUAL-MOTOR INTEGRATION SUBJECTS (HVMI)

ON CARROW ELICITED LANGUAGE INVENTORY (CELI)

\begin{tabular}{|c|c|c|c|c|c|c|}
\hline \multirow[b]{2}{*}{ Subject } & \multirow[b]{2}{*}{ Sex } & \multirow{2}{*}{$\begin{array}{l}\text { Age } \\
\text { (mo.) } \\
\end{array}$} & \multirow{2}{*}{$\begin{array}{l}\text { VMI } \\
\text { Dev. }\end{array}$} & \multicolumn{3}{|c|}{ TOTAL SCORE } \\
\hline & & & & Raw Score & Percentile & Stanine \\
\hline HVMI-1 & $\mathrm{F}$ & 52 & 8 & 27 & 37.7 & 4 \\
\hline HVMI-2 & M & 56 & 9 & 33 & 25.4 & 4 \\
\hline HVMI-3 & M & 56 & 9 & 21 & 54.1 & 5 \\
\hline HVMI - 4 & $F$ & 51 & 8 & 29 & 33.6 & 4 \\
\hline HVMI -5 & $F$ & 53 & 9 & 11 & 83.6 & 7 \\
\hline HVMI- 6 & $\mathbf{M}$ & 52 & 9 & 19 & 59.8 & 6 \\
\hline HVMI-7 & $\mathbf{F}$ & 57 & 10 & 17 & 63.1 & 6 \\
\hline HVMI-8 & M & 52 & 8 & 10 & 86.1 & 8 \\
\hline HVMI-9 & $\mathbf{F}$ & 53 & 9 & 19 & 59.8 & 6 \\
\hline HVMI -10 & $\mathbf{F}$ & 56 & 9 & 14 & 71.3 & 6 \\
\hline HVMI-11 & F & 54 & 10 & 24 & 42.6 & 5 \\
\hline HVMI -12 & M & 53 & 9 & 11 & 83.6 & 7 \\
\hline HVMI -13 & $\mathrm{~F}$ & 57 & 9 & 12 & 80.3 & 7 \\
\hline HVMI-14 & $F$ & 54 & 10 & 27 & 37.7 & 4 \\
\hline MEAN & & 54 & 9 & 19.6 & & 5.6 \\
\hline
\end{tabular}




\section{APPENDIX J}

ERROR TYPE SCORES FROM

LOW VISUAL-MOTOR INTEGRATION SUBJECTS (LVMI)

ON THE CARROW ELICITED LANGUAGE INVENTORY (CELI)

ERROR TYPES

\begin{tabular}{|c|c|c|c|c|c|c|c|c|c|c|}
\hline \multirow{3}{*}{ Subject } & \multirow{2}{*}{\multicolumn{2}{|c|}{ Substitutions }} & \multirow{2}{*}{\multicolumn{2}{|c|}{ Omissions }} & \multirow{2}{*}{\multicolumn{2}{|c|}{ Additions }} & \multirow{2}{*}{\multicolumn{2}{|c|}{ Transpositions }} & \multirow{2}{*}{\multicolumn{2}{|c|}{ Reversals }} \\
\hline & & & & & & & & & & \\
\hline & $\underline{\mathrm{RS}}$ & \% & $\underline{\mathrm{RS}}$ & $\underline{8}$ & $\underline{\mathrm{RS}}$ & $\frac{8}{6}$ & $\underline{\mathrm{RS}}$ & $\underline{8}$ & $\underline{\mathrm{RS}}$ & $\frac{8}{2}$ \\
\hline LVMI-1 & 15 & 51.6 & 10 & 21.3 & 3 & 41.8 & 0 & 100.0 & 1 & 34.4 \\
\hline LVMI-2 & 9 & 78.7 & 11 & 18.9 & 1 & 73.0 & 0 & 100.0 & 0 & 100.0 \\
\hline LVMI-3 & 13 & 60.7 & 10 & 21.3 & 0 & 100.0 & 0 & 100.0 & 2 & 9.8 \\
\hline LVMI-4 & 14 & 56.6 & 18 & & 2 & 55.7 & 0 & 100.0 & 0 & 100.0 \\
\hline LVMI-5 & 13 & 60.7 & 6 & 44.3 & 0 & 100.0 & 0 & 100.0 & 0 & 100.0 \\
\hline LVMI-6 & 11 & 68.0 & 6 & 44.3 & 0 & 100.0 & 1 & 23.0 & 1 & 34.4 \\
\hline LVMI-7 & 12 & 62.3 & 8 & 30.3 & 1 & 73.0 & 0 & 100.0 & 0 & 100.0 \\
\hline LVMI-8 & 13 & 60.7 & 4 & 61.5 & 0 & 100.0 & 0 & 100.0 & 1 & 34.4 \\
\hline LVMI-9 & 11 & 68.0 & 4 & 61.5 & 0 & 100.0 & 0 & 100.0 & 0 & 100.0 \\
\hline LVMI-10 & 18 & 36.1 & 20 & & 0 & 100.0 & 1 & 23.0 & 1 & 34.4 \\
\hline LVMI- 11 & 12 & 62.3 & 4 & 61.5 & 2 & 55.7 & 0 & 100.0 & 0 & 100.0 \\
\hline LVMI-12 & 16 & 46.7 & 8 & 30.3 & 0 & 100.0 & 0 & 100.0 & 1 & 34.4 \\
\hline LVMI-13 & 18 & 36.1 & 11 & 18.9 & 2 & 55.7 & 0 & 100.0 & 1 & 34.4 \\
\hline LVMI-14 & 17 & 40.2 & 26 & & 2 & 55.7 & 1 & 23.0 & 0 & 100.0 \\
\hline LVMI-15 & 13 & 60.7 & 9 & 26.2 & 3 & 41.8 & 0 & 100.0 & 1 & 34.4 \\
\hline MEAN & 13. & & 10 & & 1. & & .2 & $\therefore$ & .6 & \\
\hline
\end{tabular}


APPENDIX K

ERROR TYPE SCORES FROM

HIGH VISUAL-MOTOR INTEGRATION SUBJECTS (HVMI)

ON THE CARROW ELICITED LANGUAGE INVENTORY (CELI)

ERROR TYPES

\begin{tabular}{|c|c|c|c|c|c|c|c|c|c|c|}
\hline Subject & Subs & Eutions & Omi & Lons & Add: & Eions & Trans & sitions & Reve & ersal: \\
\hline & RS & 密 & $\underline{\mathrm{RS}}$ & $\frac{8}{6}$ & $\underline{\mathrm{RS}}$ & $\frac{z}{2}$ & RS & z & RS & $\underline{q}$ \\
\hline HVMI-1 & 13 & 60.7 & 12 & 18.0 & 0 & 100.0 & 1 & 23.0 & 0 & 100 \\
\hline HVMI-2 & 16 & 46.7 & 11 & 18.9 & 5 & 23.0 & 0 & 100.0 & 1 & 34 \\
\hline HVMI-3 & 7 & 80.2 & 12 & 18.0 & 2 & 55.7 & 0 & 100.0 & 0 & 100. \\
\hline HVMI-4 & 19 & 32.0 & 10 & 21.3 & 0 & 100.0 & 0 & 100.0 & 0 & 100 \\
\hline HVMI-5 & 8 & 86.9 & 3 & 70.5 & 0 & 100.0 & 0 & 100.0 & 0 & 100. \\
\hline HVMI- 6 & 8 & 86.9 & 7 & 36.9 & 2 & 55.7 & 0 & 100.0 & 2 & 9 \\
\hline HVMI-7 & 10 & 71.3 & 5 & 50.8 & 1 & 7.30 & 0 & 100.0 & 1 & 34. \\
\hline HVMI-8 & 4 & 97.5 & 5 & 50.8 & 0 & 100.0 & 1 & 23.0 & 0 & 100 \\
\hline HVMI-9 & 9 & 78.7 & 9 & 26.2 & 0 & 100.0 & 0 & 100.0 & 1 & 34. \\
\hline HVMI-10 & 4 & 97.5 & 8 & 30.3 & 1 & 7.30 & 0 & 100.0 & 1 & 34 \\
\hline HVMI-II & 12 & 62.3 & 12 & 18.0 & 0 & 100.0 & 0 & 100.0 & 0 & 100. \\
\hline HVMI -12 & 8 & 86.9 & 3 & 70.5 & 0 & 100.0 & 0 & 100.0 & 0 & 100. \\
\hline HVMI-13 & 6 & 93.4 & 6 & 44.3 & 0 & 100.0 & 0 & 100.0 & 0 & 100 \\
\hline IVMI-14 & 13 & 60.7 & 13 & 15.6 & 0 & 100.0 & 0 & 100.0 & 0 & 100 \\
\hline
\end{tabular}

MEAN

9.8

8.2

.8

.1

.4 
罗


包 H

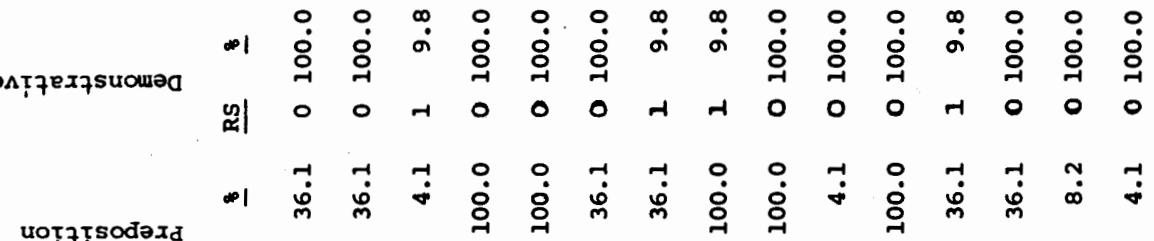
今管 田

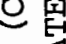






